Ranvier' suggested that the myelin can be considered to be included within its Schwann cell as a fat droplet in a fat cell, and hinted at the possible importance of its surface tension. Several observations indicate that each whole internodal segment can be regarded as a drop, elongated to a length of as much as $1.2 \mathrm{~mm}$. on a mammalian nerve fibre $20 \mu$ in diameter (Fig. 5). If a piece of rabbit's nerve is placed in hypotonic Ringer's solution (say 0.6 or 0.3 per cent) at $37^{\circ} \mathrm{C}$. it soon becomes very turgid, and material is expelled from the ends to form mushroom-like outgrowths. Incidentally, as Ranvier pointed out in interpreting the effects of treating nerves with water, this provides further evidence that the contents of a nerve fibre are fluid and can move longitudinally. At the same time, the myelin shows remarkable movements, flowing over the surface of the axon, which it leaves bare for quite long stretches at the nodes (Fig. 6). Later the myelin may subdivide into shorter segments. These phenomena can be explained as follows. The swelling is mainly due to osmosis across the membranes at the surface of the axons, the latter increasing in volume. This produces a tendency to increase the area of the myelin, which rounds up under its surface tension, leaving the axon bare at the nodes.

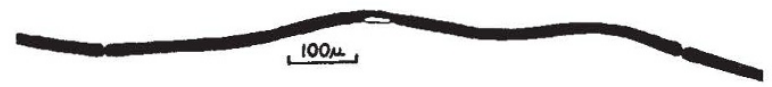

Fig. 5. NORMAL NERVE FIBRE, SHOWING A SINGLE INTERNODE WITH THE SCHWANN CELL NUCLEUS AT ITS CENTRE.

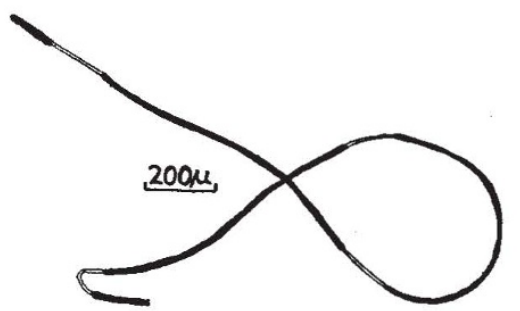

Fig. 6. FIBRE WHICH HAD BEEN FOR THREE HOURS IN DILUTED RINGER'S SOLUTION $(0.3$ PER CENT), SHOWING RETRACTION OF THE MYELIN AT THE NODES.

The experiment gives a clue to the factors controlling node-length during development. The myelin is laid down as the fibre is increasing in diameter, being first formed in the neighbourhood of the Schwann nuclei, which are spaced at more or less regular intervals along the fibre ${ }^{10}$. In the early stages, quite long regions of axon are left bare at the nodes. As the fibre grows in length and diameter the myelin continually tends to round up, as in the experiment with hypotonic solutions, and this prevents the individual segments from running together to make a continuous cylinder. By the time growth in length and diameter have ceased, the inturning of the neurilemma and the presence of a special 'cementing disc' (c, Fig. 1) at the node maintain the separation. During growth the segments of myelin increase in length but not in number. The first fibres to medullate are those which will ultimately become the largest, and these thus come to have the longest segments, whereas the smaller fibres, medullating later, have proportionately shorter and more numerous internodes. In confirmation of this hypothesis Mr. A. Vizoso, in this department, has recently found that after regeneration of an adult nerve for periods of more than a year, the internode-lengths remain short, even on the largest fibres. The internode-length is therefore not a function of diameter as such, but is determined by the relation between time of medullation and subsequent growth. Drs. F. K. Sanders and D. Whitteridge measured the conduction velocity of the nerves studied by Vizoso and found it similar to that of normal fibres of the same diameter, in spite of the short segments. Evidently conduction velocity does not have a close relationship to internode-length. Although the function of the nodes remains obscure, it may be that they serve to prevent movement of the fluid within the fibres. The aggregate of forces produced by the surface tension at the ends of a series of droplets is considerable.

Fibres of the central nervous system are usually without nodes, and lack the definite tubes which are present in peripheral nerve, no doubt to meet the stresses imposed by movement. In the absence of the tubes the myelin of the central fibres presumably wets the material which surrounds it, and therefore does not divide into segments. In confirmation of this is the fact that the central fibres rarely show incisures. They may develop an unduloid outline, but then proceed to break outwards, forming spheres and other figures at the crests of the waves.

There is obviously much to be done to confirm and extend this view of the nature of nerve fibres. The presence of the unduloid outlines and the forms seen during degeneration show quite decisively that the axon and myelin behave partly as liquids the surface tension of which affects their shape, and it seems likely that the intra-axonic pressure has an important influence on the stability of the fibre.

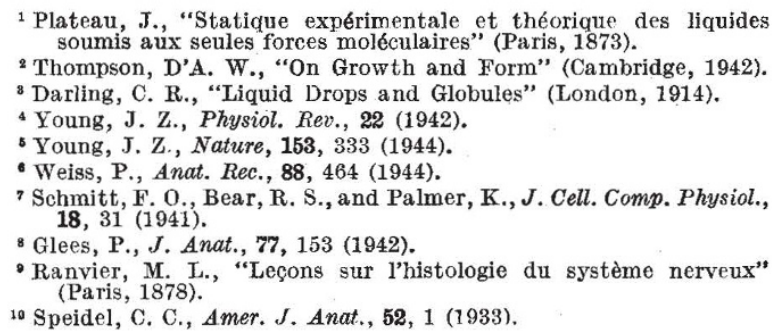

\section{ENGINEERING AND INDUSTRY IN RECONSTRUCTION}

TN his inaugural address on October 12 to the Institution of Electrical Engineers, Sir Harry Railing made an assessment of the extent to which engineers, particularly those in the electrical industry, can and should contribute to the solution of some post-war problems. A broader understanding of sociological problems has become essential for the engineer, for the products of his technical skill affect every human individual and human organization. A greater understanding of science in general and engineering in particular has become essential for every citizen, not necessarily in the form of detailed knowledge, for a bett'er comprehension of life. In the logical pursuit of his mission to help the post-war world, the engineer must therefore teach the principles which underlie his work, in the hope that they may be accepted and applied.

As to some of the more specific contributions which engineers can make towards solving international and 
national post-war problems, we cannot envisage either an individual or an organization within a country, or a country within the community of nations, which will be able in future to maintain any monopoly in production, unless it can forge ahead in new developments and products, or can lead in quality or in production cost.

It is to-day more than ever essential that every individual in industry should be as highly developed and receive ás good a general education and training in his handicraft or profession as possible, and that he should be taught a deep sense of personal and collective responsibility. This means not only education in engineering, but in team-work as well ; and such education must stress the fact that anybody who accepts more from the team than he contributes, who seeks to take more out of life than he gives, constitutes a liability rather than an asset; on the other hand, every man who gives more than he receives creates values and therefore leaves something of positive value to his fellow workers at the end of his career.

Coming to the part played by industrial associations, it is now generally acknowledged that there is an ever-increasing volume of interests common to all members of a particular industry, the furtherance of which can be undertaken by such associations with great advantage both to the industry itself and to the market which it serves. Properly constituted associations have made great contributions to ordered industrial progress, and proved themselves a socially beneficial instrument through such activities as the standardization of specifications and common parts, the pooling and exchange of patents and manufacturing experience, a measure of joint research, the standardization of trading conditions, the collection of statistical information, the maintenance of good relations with other industries, and negotiations with Government departments and with labour.

So far as the position of industry within the State is concerned, we may start from two premises which to-day are generally accepted. The interests of the individual, of a group, of a class must all be subject to the proved interest of the community. With this reservation, however, a community will be most successful, advance furthest, and obtain the highest degree of development, if it allows the utmost freedom of thought, action and development to the individual and to groups of individuals. The action of any central authority should be not so much to instruct people what to do as to restrain them from actions which might be prejudicial to others.

Regarding the influence of wages, if wage-rates in a country increase more than the normal cost of living, there will generally be an increase in the volume of articles produced, owing to an increase in the effective demand. Also, with increasing wages, taken by themselves, the cost of the product increases, and therefore the quantity of goods which can be sold in the export market decreases ; or alternatively, there is an increase in the cost of raw materials and food bought in exchange. There is, therefore, a wage limit which, for a country such as Great Britain, cannot be exceeded so long as other countries lag far behind its standard of living. It is consequently of vital concern to us to-day that the living conditions of less advanced countries, especially those which have become industrialized, should approach our own, and so bring about an expansion of world demand and the possibility for us to advance further, or at any rate to maintain our own standard.
The essentials needed to maintain the advance of British industry, therefore, are first of all, measures that assure the maintenance of any lead we can gain by increased research, better education, and the development of the more complicated and advanced problems; secondly, the provision of increased capital assistance for each worker, whether it takes the forms of increased power supply, tool equipment, transport facilities, improved lighting, or working conditions in general; and thirdly, the enlightenment and education of management and labour, and indeed of every worker, both as regards his own contribution and that of each partner with whom he must work; finally, any.measures which help to increase the volume of our export business, and especially those which create expansion of world demand by raising the standard of living in backward countries.

\section{THE LISTER INSTITUTE OF PREVENTIVE MEDICINE}

$T$

HE report for 1944 of the Governing Body of the Lister Institute of Preventive Medicine again records the wide scope of the work of members of its staff. The death of Prof. W. W. C. Topley has been a severe loss to the Council, and the Governing Body also lost the services of Sir Joseph Arkwright, who has retired after long service both in administra. tion and research. Many of the staff remain in their war-time stations in laboratories in Cambridge, Oxford and elsewhere, and many of them are serving on committees set up by the Medical Research Council. Bacteriological and immunological researches in progress include work on the anti-proteus $O X 19$ serum for the treatment of louse-borne typhus, trials of which have been carried out in North Africa in co-operation with United States Army medical authorities. All the six severe cases treated with it recovered. The typing of typhoid, paratyphoid and food-poisoning bacilli with the $V i$ bacteriophage has been continued and a hitherto unknown $V i$-phage type of the typhoid bacillus has been identified. The study of dysentery prophylaxis is making good progress and valuable work is being done on the immunology and nuclear structure of the gas gangrene organisms and on hyaluronidase. In collaboration with the Stormont Laboratory of the Ministry of Agriculture, Northern Ireland, outstanding contributions have been made to the study of trichomoniasis. Biochemical studies are in progress on specific bloodgroup substances, on the action of various bacterial toxins and on gramicidin, while work on low-temperature drying of biological materials and on foetal and maternal serum is making good progress. The work on the large-scale processing of human serum and plasma for transfusion has produced valuable results. Problems arising in the kaolin processing of plasma have been solved and the Serum Unit has been filtering the entire output of the London blood transfusion depots before sending it on to Cambridge for freeze-drying.

Other work includes the cultivation of the virus of vaccinia, work on sex and other hormones and nutritional studies. The work done with the aid of volunteers at Sheffield has indicated how large are the vitamin A reserves of the liver of healthy human adults. Studies of the nutritive value of the potato have shown that potatoes are a rich source of vitamin 